\title{
Contextual cues and the retrieval of competing memories of goal events
}

\author{
STEVEN J. HAGGBLOOM and KELLY M. MORRIS \\ Arkansas State University, State University, Arkansas
}

\begin{abstract}
In Experiment 1, four groups of rats were initially trained on a discrimination which established a stimulus as a signal for reinforcement. That signal was then presented during subsequent partial reinforcement training in a way that could potentially interfere with retrieval of the memory of nonreinforcement $\left(\mathrm{S}^{\mathrm{N}}\right)$ on the preceding trial either because (1) the storage and retrieval contexts for $\mathrm{S}^{\mathrm{N}}$ were different (retrieval failure hypothesis), or (2) the memory of reinforcement produced by the signal acted as a competing memory (competing memory hypothesis). Experiment 1 supported the competing memory hypothesis. In Experiment 2, we investigated the effect of stimulus change on the capacity of the context to retrieve a competing memory of a temporally remote reinforcement event with which the context was strongly associated. Retrieval of a competing memory was impaired by differences between the storage and retrieval contexts in a manner analogous to the effect of context on retrieval of a reinforcement event memory from an immediately preceding trial.
\end{abstract}

Memory retrieval is impaired if the constellation of stimuli present during retrieval (the retrieval context) is sufficiently different from that present at the time of storage (the storage context). This familiar contextual change effect is usually attributed to retrieval failure: the altered context lacks sufficient information for subjects to retrieve the target memory. Retrieval failure has been extensively investigated in animal learning (e.g., Capaldi, 1971, Experiment 4; Capaldi, Miller, Alptekin, Barry, \& Haggbloom, 1991; Capaldi, Nawrocki, Miller, \& Verry, 1986; Haggbioom, 1980; Jobe, Mellgren, Feinberg, Littlejohn, \& Rigby, 1977; Spear, 1978).

We report two experiments concerned with another basis for contextual change effects, whereby the altered context can serve as a signal to retrieve a competing memory if that context has been regularly associated with some event. This sort of contextual change effect has been less extensively investigated, especially in appetitive instrumental learning. Bouton and his associates (see, e.g., Bouton, 1991), however, have shown that certain interference effects in classical conditioning occur when the context retrieves a competing conditioned stimulus-unconditioned stimulus (CS-US) association. Similarly, Spear et al. (1980) reported impaired active and passive avoidance when the test context retrieved a competing memory.

Haggbloom (1988) and Haggbloom, Lovelace, Brewer, Levins, and Owens (1990) recently reported contextual change effects in appetitive instrumental learning which they too attributed to competing memories. In those experiments, the target memories were occasioned by reinforcement $(R)$ and nonreinforcement $(N)$, denoted here

Correspondence concerning this article should be addressed to $S$. J. Haggbloom, P.O. Box 2127, State University, AR 72467. as $S^{R}$ and $S^{N}$, respectively. Retrieval of $S^{R}$ or $S^{N}$ on selected learning trials was inferred from resistance to extinction. To see how extinction provides this information, consider a conventional partial reinforcement situation in which some $\mathrm{N}$ trials are followed by $\mathrm{R}$ trials (N-R transitions) and all trials occur in the same context. Such N-R transitions increase resistance to extinction (Capaldi, 1966). The reason for this, according to a memory view (Capaldi, 1971), is that $S^{N}$ is retrieved on the $R$ trial of N-R transitions and thereby acquires the capacity to signal $\mathbf{R}$. Stimuli that signal $\mathbf{R}$ elicit vigorous responding, and because $S^{N}$ is retrieved on extinction trials, responding during extinction following partial reinforcement training with N-R transitions is persistent (i.e., resistant to extinction).

Haggbloom (1988) referred to the memory of a temporally remote $\mathrm{R}$ or $\mathrm{N}$ event that is retrieved by a signal as a signal-generated memory and to the memory of a goal event stored on one trial and retrieved on the next as an event-generated memory. In Haggbloom (1988), a signal for $\mathrm{N}$ was established in initial discrimination training and was then presented on occasional $R$ trials during a subsequent phase of consistent reinforcement training. Groups trained in this way were called signal-N groups. It was hypothesized that in the context of the signal, these groups would retrieve $S^{\mathbf{N}}$ and that the signal-generated $S^{\mathbf{N}}$ would then compete with and replace the event-generated $S^{R}$ from the prior trial as the operative memory. If so, signal$\mathrm{N}$ groups would be conditioned to respond as though they had actually received $N-R$ transitions. In fact, these groups were more resistant to extinction than consistent reinforcement control groups in each of five experiments. Indeed, they were as resistant to extinction as groups given actual N-R transitions during partial reinforcement training (Haggbloom, 1988, Experiments 4 and 5). 
Using procedures analogous to those just described (cf. Haggbloom, 1988), Haggbloom et al. (1990) established a cue as a signal for $R$ and later presented that stimulus on the $\mathrm{R}$ trial of $\mathrm{N}-\mathrm{R}$ transitions during a subsequent phase of partial reinforcement training. Groups trained in this way were called signal- $R$ groups. It was hypothesized that in the context of the signal, signal-R groups would retrieve $\mathrm{S}^{\mathrm{R}}$ and that this signal-generated $\mathrm{S}^{\mathrm{R}}$ would then replace the event-generated $\mathrm{S}^{\mathrm{N}}$ from the prior trial as the operative memory. If so, this would prevent $S^{N}$ from becoming a signal for reinforcement.

In agreement with this analysis, resistance to extinction was decreased, and the partial reinforcement extinction effect was eliminated, in signal-R groups. Indeed, Haggbloom et al. (1990, Experiment 3) reported that signal-R groups were no more resistant to extinction than were groups given an actual reinforcement during the intertrial interval (see Capaldi \& Spivey, 1963).

The experiments just reviewed are consistent with the view that a signal (or context) associated in training with either $\mathrm{R}$ or $\mathrm{N}$ will, when subsequently presented, retrieve $S^{R}$ or $S^{N}$, respectively, even though the signal is presented on trials that are temporally quite remote from those on which the memory was stored. Moreover, if the signal constitutes an altered context, the retrieved memory will compete with and replace the memory for the prior-trial event that would otherwise have been operative. In the experiments reported by Haggbloom (1988), retrieval of $\mathrm{S}^{N}$ as a competing memory in the signal- $\mathrm{N}$ groups resulted in learning about $S^{\mathbf{N}}$, later manifested as increased resistance to extinction, that otherwise would not have occurred. In the experiments reported by Haggbloom et al. (1990), retrieval of $S^{R}$ as a competing memory in the signal-R groups interfered with learning about $S^{N}$ that otherwise would have occurred, and this was manifested in decreased resistance to extinction.

The purpose of our first experiment was to investigate two alternative interpretations of the decreased resistance to extinction previously reported for signal-R groups by Haggbloom et al. (1990). Those alternatives, discouraged but not eliminated by Experiment 2 of that prior report, are described below. In our second experiment, we investigated whether the capacity of the signaling context to retrieve a competing memory depends on similarity between the context associated with that memory in initial training and that used subsequently to generate its retrieval.

\section{EXPERIMENT 1}

During the partial reinforcement training for signal-R groups employed by Haggbloom et al. (1990), the storage context for $\mathrm{S}^{\mathbf{N}}$ was different from the retrieval context because the retrieval context included the signal for $R$. In other words, the cues present on the nonreinforced trials of the N-R transitions were necessarily different from those on reinforced trials because of the added presence of the singal. Thus, the reduced resistance to extinction in these groups, which was attributed to the replacement
Table 1

Representative Phase 2 Reward Schedule

\begin{tabular}{|c|c|c|c|}
\hline Group & $\begin{array}{c}\text { Storage/Retrieval } \\
\text { Context Similarity } \\
\end{array}$ & $\begin{array}{c}\text { Associative History } \\
\text { of the } \\
\text { Retrieval Context }\end{array}$ & Schedule \\
\hline Event-N/S & same & novel & $R \underline{N} R \underline{N}$ \\
\hline Signal-R/S & same & signal for $R$ & $R \underline{N R} R \overline{N R}$ \\
\hline Event-N/D & different & novel & R $\overline{\overline{\mathrm{N}} \underline{\mathrm{R}}} \mathrm{R} \overline{\overline{\mathrm{N}} \underline{\mathrm{R}}}$ \\
\hline Signal-R/D & different & signal for $R$ & R N $\underline{\underline{R}} R \mathbf{N} \underline{\underline{R}}$ \\
\hline
\end{tabular}

Note- $R$, reinforcement; $N$, nonreinforcement. Underscored trials occurred in same context: single underscore = novel context; double underscore $=$ context established as signal for $\mathbf{R}$.

of $S^{N}$ by signal-generated $S^{R}$ as the operative memory, could have been due instead simply to a failure of the altered context to retrieve $S^{\mathbf{N}}$. Haggbloom et al. (1990) reported that a group given partial reinforcement training in which the retrieval context for $S^{N}$ was novel and different from the storage context, but which did not signal $S^{R}$ as a competing memory, did not show any evidence of retrieval failure. That finding suggests that the failure of signal-R groups to learn to respond to $S^{N}$ was not merely due to its failure of retrieval because of the context change. Our first experiment, however, provided a stronger test of the retrieval failure account. Here, in addition to the context change condition employed by Haggbloom et al. (1990, Experiment 2), we employed a signal$\mathbf{R}$ group given no context change.

In Experiment 1, four groups were trained in Phase 1 on a go/no-go runway discrimination problem on which $\mathbf{R}$ trials were signaled by the presence of a tactile stimulus (textured floor) for two groups and by a darkened (covered) runway for the other two groups. $\mathrm{N}$ trials were signaled by the absence of the tactile cue and runway cover, respectively. Phase 1 served to provide us with four groups given comparable discrimination training, but with the tactile cue established as a signal for $R$ in just two of the groups.

In Phase 2, all groups received identical partial reinforcement training on schedules that contained two daily $\mathrm{N}-\mathrm{R}$ transitions. The two trials of each N-R transition constitute, respectively, storage and retrieval trials for $S^{N}$, the target memory. Table 1 shows a representative reinforcement schedule. Underscored trials occurred in the tactile stimulus context which was novel for two groups (single underscore) and signaled $\mathbf{R}$ for the remaining two groups (double underscore). As can be seen in Table 1, two groups were trained in a same-context condition (S), meaning that the tactile stimulus was present on both the storage and retrieval trials of each N-R transition. The remaining two groups were trained in a different-context condition (D), meaning that the tactile stimulus was present only on retrieval trials.

For one group in the same condition, Group Event-N/S, and one in the different condition, Group Event-N/D, the tactile stimulus had not been established in Phase 1 as a signal for R; instead, these groups learned a brightness discrimination in Phase 1, so the tactile stimulus was novel 
in Phase 2. Consequently, Group Event-N/S should, on the $\mathrm{R}$ trial of $\mathrm{N}-\mathrm{R}$ transitions, retrieve $\mathrm{S}^{\mathrm{N}}$ occasioned by the actual $N$ event on the immediately preceding trial. This should permit $S^{N}$ to become a signal for $R$, and thus produce substantial resistance to extinction in this group. Resistance to extinction in Group Event-N/D, relative to Group Event N/S, would indicate the extent to which retrieval of $S^{\mathrm{N}}$ was impaired by a context change created by the presence of the novel tactile stimulus. If Group Event-N/D showed decreased resistance to extinction, this would indicate impaired retrieval of $S^{N}$ on the reinforced trials.

The second group in the same-context condition, Group Signal-R/S, was treated exactly as Group Event-N/S, and the second group in the different-context condition, Group Signal-R/D, was treated exactly as Group Event-N/D, except that the tactile stimulus was a signal for $R$ in both groups. Both groups should store $S^{N}$ on the storage trial of N-R transitions, but the tactile stimulus should retrieve $S^{R}$ on the retrieval trial thereby preventing $S^{N}$ from becoming a signal for $R$. Thus, Groups Signal-R/S and Signal-R/D should respond similarly in extinction and both groups should be less resistant to extinction than Group Event-N/S. Reduced resistance to extinction in both signal-R groups would support the interpretation of Haggbloom et al. (1990) that the signal retrieves a competing memory. On the other hand, if resistance to extinction was diminished in Group Signal-R/D alone, that would indicate that the effect was due to an altered retrieval context (i.e., an inability to retrieve $S^{N}$ from the prior trial) and not to the generation of a competing memory.

As another alternative to the competing memory explanation of the reduced resistance to extinction reported for signal-R groups, Haggbloom et al. (1990) noted that those groups may have been conditioned to a compound stimulus consisting of $S^{N}$ plus the tactile stimulus (signal for $R)$. In that event, resistance to extinction might be reduced in signal- $R$ groups because extinction trials occurred in the absence of the tactile stimulus and, thus, in the absence of the presumed compound. This compound stimulus hypothesis was tested here by conducting extinction for one half of the subjects in each group in the context of the tactile stimulus. If those subjects showed greater resistance to extinction than subjects tested without the tactile stimulus, this would lend support to the compound stimulus hypothesis.

\section{Method}

Subjects. The subjects were 24 male rats, approximately 100 days old at the beginning of experimental training, bred in the laboratory from Holtzman stock. The rats were housed in individual cages and had access to water throughout the experiment.

Apparatus. The apparatus consisted of a single straight alleyway $235 \mathrm{~cm}$ long, $10 \mathrm{~cm}$ wide, and $15 \mathrm{~cm}$ high. The alleyway was made of wood and had a hinged hardware cloth top. The initial $25 \mathrm{~cm}$ and final $25 \mathrm{~cm}$ of the runway constituted start- and goalboxes, respectively. The startbox and goalbox were separated from the rest of the runway by manually operated guillotine doors. Three clocks $(.01 \mathrm{sec})$ recorded start, run, and goal times over respective distances of $20 \mathrm{~cm}$, the next $150 \mathrm{~cm}$, and the next $30 \mathrm{~cm}$ from the startbox door. Opening of the startbox door activated the first clock, and photoelectric circuitry controlled its offset and the operation of the remaining two clocks. Positioned against the end wall of the goalbox was an unpainted goal cup constructed by drilling a 6-cm diam hole in a small block of wood. The tactile stimulus was .5-in. hardware cloth cut to fit on the floor of the startbox and runway up to the goalbox door. The brightness stimulus consisted of opaque covers made of plywood and placed over the startbox and runway up to the entrance to the goalbox.

Procedure. Two weeks before the start of training, and throughout the experiment, the rats were on food deprivation, receiving $14 \mathrm{~g}$ of lab chow per day minus the weight of food pellets received during training. On Days 12-14 of deprivation, the rats were handled in squads of two for 2-3 min per squad. After being handled on those days, the rats were fed eight $.045-\mathrm{g}$ Noyes Formula A food pellets from a small dish in their home cages. Six rats were randomly assigned to each of four groups, Groups Signal-R/S, Signal-R/D, Event-N/S, and Event-N/D.

Phase 1. All four groups initially received 12 days of discrimination training consisting of signaled $R$ trials and unsignaled $\mathbf{N}$ trials. The purpose of this training was simply to establish different signals for $\mathbf{R}$ in the different groups. Thus, $\mathbf{R}$ trials were signaled by the presence of the tactile stimulus for Groups Signal-R/S and SignalR/D, and by the brightness stimulus for Groups Event-N/S and Event-N/D. For all groups, Phase 1 training involved six trials per day administered in two three-trial sessions. The reward sequence was RRN in Session 1 and RNN in Session 2 on odd-numbered days. On even-numbered days, RNN was given in Session 1 followed by RRN in Session 2. The intertrial interval within sessions was about 3-4 min, and the intersession interval was about $25 \mathrm{~min}$.

Phase 2. All four groups received 5 days of partial reinforcement training on the same schedules of $R$ and $N$ trials. In order, the schedules were RNRRNR, NRRNRR, RRNNRR, RNRRNR, and NRRNRR. Groups differed with respect to the trials on which the tactile stimulus occurred. The placement of the tactile stimulus was varied to produce identical storage and retrieval contexts for $S^{N}$ for two groups (i.e., Groups Event-N/S and Signal-R/S) and different contexts for the remaining two groups (i.e., Groups EventN/D and Signal-R/D; see Table 1). For Groups Event-N/S and Signal-R/S, the tactile stimulus was presented on both the $\mathbf{N}$ and the $R$ trials of all N-R transitions-for example, on Trials 2, 3, 5 , and 6 of Day 1. For Groups Event-N/D and Signal-R/D, the tactile stimulus was present only on the $R$ trial of N-R transitionsfor example, Trials 3 and 6 of Day 1. Groups also differed in Phase 2 in that, because of the stimulus employed during Phase 1 discrimination training, the tactile stimulus signaled $\mathbf{R}$ for Groups Signal-R/S and Signal-R/D, or was novel and thus signaled neither $\mathrm{N}$ nor $\mathrm{R}$ for Groups Event-N/S and Event-N/D. The intertrial interval was the same as in Phase 1.

Extinction. Eight days of extinction with three trials per day followed the completion of Phase 2. The tactile stimulus was present on all extinction trials for one half of the subjects in each group and was absent for the remainder of the subjects. As before, the intertrial interval was 3-4 min.

Trial administration procedures. A trial began with the opening of the startbox door approximately $2-3 \mathrm{sec}$ after the rat was placed in the apparatus. The rats were run in squads containing 1 rat from each group. The order of running within a squad varied randomly each day, but the order of successive squads was constant across days. Reinforcement on R trials consisted of eight .045-g Formula A Noyes food pellets. On $\mathrm{N}$ trials, the rats were confined to the unbaited goalbox for $20 \mathrm{sec}$. 
A maximum time of $60 \mathrm{sec}$ was allowed in each section of the runway. If this was exceeded in any section, the additional time was added to the score of the next section. If the rat did not enter the goalbox in $180 \mathrm{sec}$, it was placed in the goalbox.

\section{Results}

The pattern of results in extinction, which was of primary interest, was the same in each section of the runway and over the total length of the runway. However, group differences fell short of conventional levels of significance when total speeds were analyzed $(.05<p<$ $.06)$, but were reliable in the goal section. Therefore, analyses of goal speeds are reported.

Phase 1. In Phase 1 (data not shown), each group learned to run faster on signaled $R$ trials than on unsignaled $\mathrm{N}$ trials. The mean running speeds (in centimeters/ second) on R trials for Groups Event-N/S, Event-N/D, Signal-R/S, and Signal-R/D were 69.08, 68.17, 67.02, and 66.30 , respectively. The mean running speeds on $\mathrm{N}$ trials for those groups, in the same order, were 24.38, $20.48,50.50$, and 33.48. A 2 (same vs. different context in Phase 2) $\times 2$ (event- $N$ vs. signal-R) $\times 2$ (discriminanda) $\times 3$ (trial) analysis of variance (ANOVA) was applied to speeds on the last day of Phase 1 . The observation that subjects ran faster on $\mathrm{R}$ than on $\mathrm{N}$ trials was supported by a significant effect of discriminanda $[F(1,18)=$ $82.88, p<.01]$. The fact that the difference between $\mathrm{R}$ and $\mathrm{N}$ trial speeds was larger in event- $\mathrm{N}$ than in signal- $\mathrm{R}$ groups contributed to a significant discriminanda $\times$ event$\mathrm{N}$ versus signal-R interaction $[F(1,18)=7.64, p<.05]$. Planned comparisons showed that all groups ran faster on R trials than on $\mathrm{N}$ trials [smallest $F(1,18)=4.62, p<$ .05 , for Group Signal-R/S].

Phase 2. There were no differences among the four groups in speed of running on the last day of Phase 2. Mean running speeds ranged from 74.72 in Group SignalR/D to 80.92 in Group Event-N/S. A 2 (same vs. different) $\times 2$ (event- $N$ vs. signal-R) $\times 6$ (trial) ANOVA applied to speeds on the last day of Phase 2 yielded no reliable terms [all $F$ s $<1$ for between-subjects terms, and for within-subjects terms largest $F(5,90)=1.95$ for the trials main effect].

Extinction. Figure 1 shows the mean running speed of each group on the last day of Phase 2 and in extinction in blocks of two days. There were no differences in resistance to extinction as a function of whether subjects received extinction trials with the tactile stimulus present or absent. Thus, running speeds in Figure 1 are collapsed across that variable.

Figure 1 shows that Groups Event-N/S and Event-N/D were equally resistant to extinction and ran faster throughout extinction than Groups Signal-R/S and Signal-R/D, which in turn did not differ from each other. A 2 (same vs. different retrieval context) $\times 2$ (signal-R vs. event-N) $\times 2$ (presence vs. absence of TS in extinction) $\times 8$ (day) $\times 3$ (trials) ANOVA was applied to goal speeds. The ANOVA showed that the event- $N$ groups were more resistant to extinction than the signal-R groups $[F(1,14)=$ $5.29, p<.05$ ]. No other between-subjects variables, and

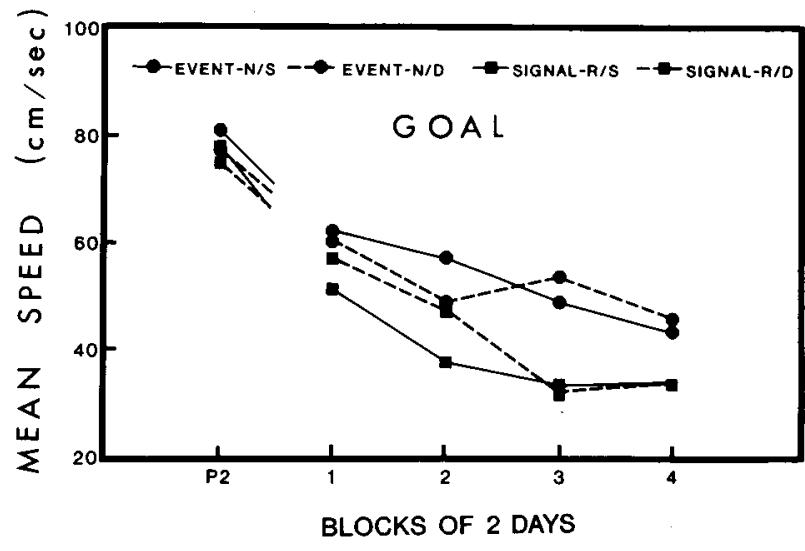

Figure 1. Mean running speed for each group in the goal section of the runway on the last day of Phase 2 , and in extinction in blocks of 2 days.

no interactions involving between-subjects variables, were significant (all $F \mathrm{~s}<1$ ).

\section{Discussion}

Groups Event-N/S and Event-N/D responded alike in extinction and were more resistant to extinction than Groups Signal-R/S and Signal-R/D, which also responded alike. The reduced resistance to extinction shown here by signal-R groups agrees with similar results reported by Haggbloom et al. (1990).

These results were not affected by presence versus absence of the tactile stimulus on extinction trials. Thus, decreased resistance to extinction in the signal- $R$ groups is not due to conditioning to a compound stimulus consisting of $S^{\mathbf{N}}$ and the tactile stimulus.

Our present procedures distinguished between retrieval failure caused by a context change, and context-generated (i.e., signal-generated) retrieval of a competing memory. Our results support the view advanced by Haggbloom et al. (1990) that the reduced resistance to extinction in signal-R groups is explained by the associative history of the retrieval context for $S^{N}$ and is not attributable to simple retrieval failure. In Group Event-N/D, the retrieval context included the tactile stimulus but the storage context did not. In Group Event-N/S, the tactile stimulus was present on both the storage and the retrieval trials. The tactile stimulus was not a signal for a competing memory in either of those groups, and their equal resistance to extinction indicates that they retrieved event-generated $S^{N}$ equally well on retrieval trials during partial reinforcement training. The reduced resistance to extinction in Groups Signal-R/S and Signal-R/D indicates, by contrast, that retrieval of $S^{N}$ was impaired by a context associated with $\mathbf{R}$. The signal for $\mathbf{R}$ diminished or negated the usual effect (cf. Capaldi, 1966) of N-R transitions on resistance to extinction. Furthermore, resistance to extinction was reduced equally in the two signal- $R$ groups, indicating that this effect was not due simply to a disparity between stor- 
age and retrieval contexts. Rather, it appears that the retrieval context - the presentation of the signal-actively retrieved a competing memory, $S^{R}$.

The results of this experiment, and those reported by Haggbloom (1980, 1988) and Haggbloom et al. (1990), indicate that a goal-event memory may be retrieved in a context that is slightly different from the storage context (e.g., Group Event-N/D here). However, if the retrieval context has been established as a signal for a goal event different from that experienced on the preceding trial, it will retrieve the memory of its associated event. This signal-generated memory will then replace the memory of the goal event from the preceding (storage) trial, and responding will then be conditioned to this "new" operative memory.

\section{EXPERIMENT 2}

In many situations, memory retrieval is impaired by a disparity between the storage and retrieval contexts even though the retrieval context does not retrieve an interfering or competing memory. Retrieval of goal-event memories, too, may sometimes be impaired by a context change that does not retrieve an interfering or competing memory (e.g., Capaldi et al., 1991; Capaldi et al., 1986; Jobe et al., 1977). The purpose of our second experiment was to investigate whether retrieval of a signal-generated memory is similarly impaired by a change in contextspecifically, by changing the attributes of the signal.

In Experiment 2, we varied the degree of similarity between the context established as a signal for a goal-event memory (in this case $S^{N}$ ) and the context presented to retrieve $S^{N}$ on selected learning trials. We hypothesized that the absence of some of the cues established as a signal for $\mathrm{N}$ during attempts to retrieve $S^{\mathrm{N}}$ would cause impaired retrieval of the signal-generated $S^{N}$.

Three groups of subjects initially received discrimination training (cf. Haggbloom, 1988) designed to establish either a single stimulus (Group 1-1), or a threestimulus compound (Groups 3-3 and 3-1), as a signal for nonreinforcement. In Phase 2, all three groups received consistent reinforcement training with one (Group 3-1) or all (Groups 1-1 and 3-3) of those stimuli presented on two $R$ trials each day.

As noted above, presentation of a signal for $\mathrm{N}$ retrieves $S^{N}$, which can then replace $S^{R}$ as the operative memory. Consequently, subjects learn to respond to $S^{\mathrm{N}}$ as though actually given partial reinforcement training (i.e., as though there were actually $\mathrm{N}$ trials). Thus, relative to a control group, they show increased resistance to extinction, an effect called the signal-generated partial reinforcement extinction effect (PREE) (Haggbloom, 1988). We predicted that Groups 1-1 and 3-3 would show a sizeable and comparable signal-generated PREE, and that the signal-generated PREE would be reduced or eliminated in Group 3-1. The reason is that for Groups 1-1 and 3-3, the same stimuli originally established as signals for $\mathbf{N}$ are presented to retrieve $S^{N}$ in Phase 2. For Group 3-1, on the other hand, only one of the three cues established as signals for $\mathrm{N}$ is presented in Phase 2, so retrieval of $\mathrm{S}^{\mathrm{N}}$ under these conditions should be impaired.

\section{Method}

Subjects. The subjects were 24 male rats bred in the laboratory from Holtzman stock. They were housed and maintained as in Experiment 1 . The experiment was conducted in two replications with 3 rats per group in each replication. Within a replication, rats did not vary in age by more than 4 days. Across replications, the rats ranged in age from 90 to 110 days old.

Apparatus. The runway, tactile stimulus, and brightness stimulus were as previously described. A plywood pretrial feeding box measuring $25 \mathrm{~cm}$ on all sides and $20 \mathrm{~cm}$ high was located on a table adjacent to the startbox.

Procedures. All procedures prior to Day 1 of training were the same as in Experiment 1. In both replications, 3 rats were randomly assigned to each of four groups identified as Groups 3-3, 3-1, 1-1 (signal-N groups), and Group CR (continuous reinforcement).

Phase 1. Discrimination training began on Day 15 of deprivation and continued for 6 days. Groups 3-3, 3-1, and 1-1 received two daily three-trial sessions as described for Experiment 1 (i.e., RRN followed by RNN on odd-numbered days and RNN followed by RRN on even-numbered days). For Group CR, all Phase 1 trials were rewarded. The intertrial interval was 2-3 min within sessions, and there was a minimum of $20 \mathrm{~min}$ between sessions.

One of the discriminative cues used to signal $\mathrm{N}$ trials here was a pretrial feeding that consisted of removing the rat from the intertrial holding cage and placing it in the pretrial feeding box, which was baited with eight $.045-\mathrm{g}$ food pellets. A nonreinforced runway trial was then administered $3-5 \mathrm{sec}$ after the rat consumed the pretrial food (see Haggbloom, 1988).

All N trials for Groups 3-3 and 3-1 were signaled by a compound stimulus consisting of a pretrial feeding and presence of the tactile and brightness stimuli in the runway. In both replications, $\mathrm{N}$ trials for Group 1-1 were signaled only by the pretrial feeding for 1 subject, the tactile stimulus for another, and the brightness stimulus for the 3rd subject. All reinforced trials for these groups were unsignaled. For Group CR, all trials were reinforced and the $R$ trials that corresponded to signaled $\mathbf{N}$ trials for the other three groups were also "signaled" in Group CR. The subjects in Group CR experienced the three signals both individually and as a compound stimulus.

Phase 2. All four groups received four $R$ trials on each of 6 oddnumbered consistent reinforcement training days. Signal presentations were administered to Groups 3-3, 3-1, and 1-1 on Trials 2 and 4 (Day 1), 2 and 3 (Day 3), 3 and 4 (Day 5), 1 and 5 (Day 7), 4 and 5 (Day 9), and 2 and 3 (Day 11). The subjects in Groups 3-3 and 1-1 received the same cue(s) on signaled trials as they had in Phase 1. The subjects in Group 3-1 experienced only one of the three cues on both signaled trials on a given consistent reinforcement day. Over the six consistent reinforcement days, the subjects rotated through the three cues, with each of the 3 subjects in a replication starting the rotation with a different cue. Group $C R$ received "signaled" trials corresponding to signaled trials for the other three groups.

Consistent reinforcement training days alternated with continued discrimination training on Days $2,4,6,8$, and 10 . On those days, the signal-N groups (3-1, 1-1, and 3-3) received two unsignaled $R$ trials followed by two signaled $N$ trials. Group $C R$ received all R trials, with Trials 3 and 4 each day being "signaled" (see Haggbloom, 1988 for a rationale for the continued discrimination training days).

Extinction. Each subject received 30 extinction trials at the rate of three trials per day for 10 days. The intertrial interval was 2-3 min. None of the signals employed in Phases 1 and 2-pretrial feeding, tactile stimulus, brightness stimulus-were present on extinction trials. 


\section{Results}

Haggbloom (1988) reported that the signal-generated PREE was largest in the start section of the runway. That was true here as well, so only start speeds are reported.

Phase 1. All three signal-N groups learned to run faster on unsignaled $\mathrm{R}$ trials than on signaled $\mathrm{N}$ trials. On the last day of Phase 1, for example, mean speeds for Groups 3-3, 1-1, and 3-1 on R trials were, respectively, 25.19, 39.51 , and $35.21 \mathrm{~cm} / \mathrm{sec}$, and mean speeds on $\mathrm{N}$ trials were $2.21,11.93$, and $3.34 \mathrm{~cm} / \mathrm{sec}$. Planned comparisons showed that all three signal- $\mathbf{N}$ groups ran faster on $\mathrm{R}$ trials than on $\mathrm{N}$ trials [smallest $F(1,16)=44.01, p<.01$, for Group 1-1].

Phase 2. On unsignaled trials on the last consistent reinforcement day of Phase 2, Groups 3-3, 1-1, and 3-1 ran at nearly the same speed $(M \mathrm{~s}=45.69,46.24$, and $42.40 \mathrm{~cm} / \mathrm{sec}$, respectively) and faster than Group CR $(M=33.23 \mathrm{~cm} / \mathrm{sec})$. Groups $(4) \times$ trials $(2) \times$ replications (2) ANOVAs applied to these data showed that the relatively slow running by Group CR resulted in a reliable groups effect $[F(3,16)=6.19, p<.01]$. Planned comparisons showed that each of the three signal- $\mathrm{N}$ groups was faster than Group CR at the end of Phase 2 [smallest $F(1,16)=7.19, p<.05]$.

Extinction. Figure 2 shows mean speeds for each group on the two unsignaled trials on the last consistent reinforcement day of Phase 2 and on each day of extinction.

Groups 3-3 and 1-1 were most resistant to extinction, with Group 1-1 running slightly faster than Group 3-3 over Days 1-5 and slightly slower than Group 3-3 over Days 6-10. Group CR was least resistant to extinction, and Group 3-1 responded at an intermediate level.

Groups (4) $\times$ trials $(3) \times$ days $(10) \times$ replications $(2)$ ANOVAs were applied to start and total speeds in extinction. There were reliable differences among groups $[F(3,16)=8.44, p<.01]$, but no differences due to replications $(F<1)$, no groups $\times$ replications interaction $(F<1)$, and no groups $\times$ days interaction $[F(27,144)=$ 1.51]. Planned comparisons applied to group mean speeds

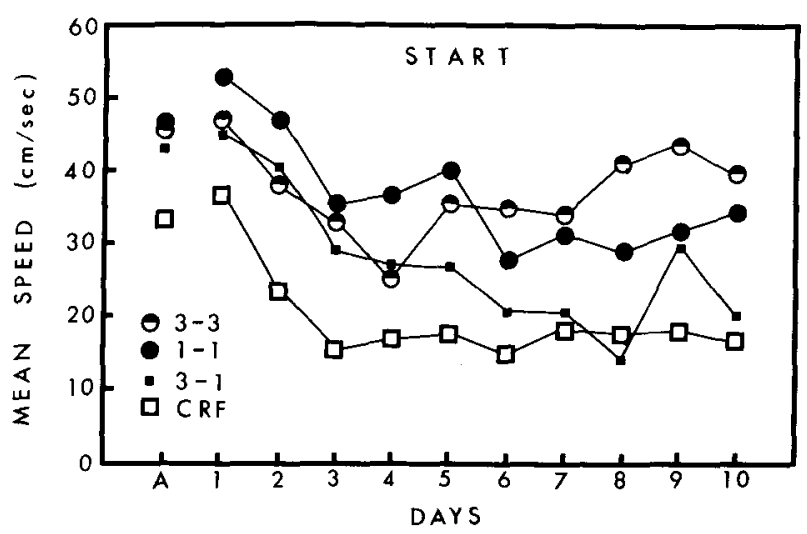

Figure 2. Mean running speed for each group in the start section of the runway on the last day of Phase 2 , and on each day of extinction. over all 30 extinction trials showed that Groups 3-3 $(M=$ $37.25 \mathrm{~cm} / \mathrm{sec})$ and $1-1(M=36.74 \mathrm{~cm} / \mathrm{sec})$ did not differ in resistance to extinction $(F<1)$, that both groups were more resistant to extinction than Group 3-1 $(M=$ $27.29 \mathrm{~cm} / \mathrm{sec}) ; F_{\mathrm{s}}(1,16)=5.91$ and 5.33 , respectively, ps $<.05$ ], and that both groups were more resistant to extinction than Group CR $[M=19.65 \mathrm{~cm} / \mathrm{sec}$; $F_{\mathrm{S}}(1,16)=18.64$ and 17.43 , respectively, $\left.p \mathrm{~s}<.01\right]$. Group 3-1 did not run reliably faster than Group CR $[F(1,16)=3.48]$.

\section{Discussion}

In Experiment 2, Groups 3-3 and 1-1, given a signal to activate $S^{\mathbf{N}}$ that consisted of the same stimulus established in Phase 1 as a signal for nonreward, were more resistant to extinction than Group CR. This signalgenerated PREE replicates previous findings that presentation of a signal for $\mathrm{N}$ on selected $\mathrm{R}$ trials during consistent reinforcement training increases resistance to extinction (Haggbloom, 1988; Haggbloom \& Brewer, 1989). The increased resistance to extinction in Groups 3-3 and 1-1 here is not likely attributable to the fact those groups ran faster than Group CR at the end of Phase 2, given that Group 3-1 ran comparably fast but did not show increased resistance to extinction. The relatively rapid rate of extinction in Group 3-1, which was given a signal that consisted of only a subset of the cues used to signal $\mathbf{N}$ in Phase 1 , is consistent with the hypothesis that the capacity of a signal to retrieve $S^{N}$ depends on the similarity between the retrieval context and the storage context.

That the signal-generated PREE is sensitive to manipulations of the similarity between the storage and retrieval contexts (i.e., that it "obeys"' a fundamental law of memory) lends support to the overall interpretation of the effect as mediated by memory processes-specifically, the behavioral control exercised by the memory of nonreward.

\section{GENERAL DISCUSSION}

The term context is widely used to refer to relatively constant, nonspecific background stimuli and certain internal (e.g., drug-induced) stimulus states. In our experiments, we manipulated "contextual" cues that were highly specific components of the stimulus complex accompanying selected learning trials, cues that are not "contextual" in the usual sense. On the other hand, the cues we employed were "contextual" in a functional sense-that is, in terms of their relationship to other stimuli and events. For example, the tactile cue experienced by signal- $R$ groups in Experiment 1 was invariably present on reinforced trials and was therefore a part of the context in which reinforcement occurred. The use of such discrete, localized stimuli as "contextual" cues is not without precedent in studies of the role of context in learning (see Thomas, 1985, for one discussion of such experiments), and memory (e.g., Hickis, Robles, \& Thomas, 1977; Zentall, 1970). We find no evidence to indicate that the use of discrete stimuli as contextual cues limits the implica- 
tions of our results for understanding contextual stimulus effects on memory retrieval.

Investigations into the effects of context on human and animal memory have focused on the fact that memory retrieval is promoted by a retrieval context that is similar to the storage context. A retrieval context that differs from the storage context may fail to support retrieval of a viable target memory because the retrieval context is lacking in information needed to activate the memory (e.g., Capaldi et al., 1986; Spear, 1978; Tulving, 1974).

Another, less extensively studied, effect of context on memory retrieval is the active recruitment of a memory that has been paired with the context. In this case, there are competing memories and the retrieval of the target memory is impaired because the context retrieves the alternate memory. This effect of context has been studied by Bouton and his colleagues (see Bouton, 1991, for a review) and by Thomas and his colleagues (see Thomas, 1981). For example, Bouton (1991) reviewed evidence that a CS that has been paired with a US and that has undergone extinction will signal either the conditioning relationship or extinction, depending on the context in which it is presented. Thomas (1981) reviewed evidence that pigeons trained on competing operant discrimination problems retrieved either the target task or the competing task, depending on the retrieval context.

Our results agree with those cited above in showing that the associative history of the retrieval context is an important determinant of retrieval. Specifically, because of its associative history, the retrieval context can retrieve a competing memory. The present results would appear to be unique, however, in one respect. Previous experiments have shown that the context can retrieve the memory of a previously acquired CS-US or stimulus (S)-response (R) association as a competing memory. In our experiments, and those of Haggbloom (1988) and Haggbloom et al. (1990), the context retrieved a competing memory of a more specific event, or type of event-that is, $S^{R}$ or $S^{N}$. Moreover, previous experiments have shown that retrieval of some target memory may be impaired by a change in stimulus context. Our second experiment extends that finding to the capacity of a context to retrieve a competing memory with which it is strongly associated; that is, the familiar context change effect occurs for signal-generated memories as it does for event-generated memories.

Our results, and similar results reported previously (e.g., Haggbloom, 1988; Haggbloom \& Brewer, 1989; Haggbloom et al., 1990), indicate that stimuli established as signals for $\mathbf{R}$ and $\mathrm{N}$ events can substitute for those events in the establishment of new associations. As suggested here and in Haggbloom (1988), this substitution is mediated by representations of $\mathrm{R}$ or $\mathrm{N}$ activated by the signal. Haggbloom (1988) noted that this view is similar to the view (e.g., Wagner, 1978) that the CS in classical conditioning evokes a representation of the US. Experi- ments by Holland (1981) and Holland and Forbes (1982) lend support to our view that signal-generated representations of $\mathrm{N}$ and $\mathrm{R}$ can substitute for those events. Those investigators reported evidence that CS-evoked representations of the US could substitute for the US in the acquisition of a conditioned flavor aversion (Holland, 1981) and the control of a conditional discrimination (Holland \& Forbes, 1982). Apparently, signal-generated representations are influential in a variety of behavioral situations.

\section{REFERENCES}

Bouton, M. E. (1991). Context and retrieval in extinction and in other examples of interference in simple associative learning. In $\mathrm{L}$. Dachowski \& C. F. Flaherty (Eds.), Current topics in animal learning (pp. 2553). Hillsdale, NJ: Erlbaum.

CaPaldi, E. J. (1966). Partial reinforcement: A hypothesis of sequential effects. Psychological Review, 73, 459-477.

CAPALDI, E. J. (1971). Memory and learning: A sequential viewpoint. In W. K. Honig \& P. H. R. James (Eds.), Animal memory (pp. 111154). New York: Academic Press.

Capaldi, E. J., Miller, D. J., Alptekin, S., Barry, K., \& HagGBLOOM, S. J. (1991). Memory retrieval and discrimination learning. Learning \& Motivation, 22, 439-452.

Capaldi, E. J., NaWrocki, T., Miller, D. J., \& Verry, D. R. (1986). Time between events as a retrieval cue: Recall and the temporal similarity between storage and retrieval intervals. Joumal of Experimental Psychology: Animal Behavior Processes, 12, 258-269.

Capaldi, E. J., \& SPIVEY, J. (1963). The effect of goal box similarity on the aftereffect of nonreinforcement and resistance to extinction. Journal of Experimental Psychology, 66, 461-465.

HAGGBLOOM, S. J. (1980). Effects of training level and locus of N-R transitions on resistance to discrimination. Psychological Record, 30, 419-422.

Haggbloom, S. J. (1988). The signal-generated partial reinforcement extinction effect. Journal of Experimental Psychology: Animal Behavior Processes, 14, 83-93.

HaGgbloom, S. J., \& BREWER, V. R. (1989). Behavioral disruption versus signal-generated memory retrieval as determinants of the signalgenerated partial reinforcement extinction effect. Bulletin of the Psychonomic Society, 27, 99-102.

Haggbloom, S. J., Lovelace, L., Brewer, V. R., Levins, S. M., \& OWENS, J. D. (1990). Replacement of event-generated memories of nonreinforcement with signal-generated memories of reinforcement during partial reinforcement training: Effect on resistance to extinction. Animal Learning \& Behavior, 18, 315-322.

Hickis, C. F., Robles, L., \& Thomas, D. R. (1977). Contextual stimuli and memory retrieval in pigeons. Animal Learning \& Behavior, $5,161-168$.

HollaND, P. C. (1981). Acquisition of representation-mediated conditioned food aversions. Learning \& Motivation, 12, 1-18.

Holland, P. C., Forbes, D. T. (1982). Control of conditional discrimination performance by CS-evoked event representations. Animal Learning \& Behavior, 10, 249-256.

Jobe, J. B., Mellgren, R. L., Feinberg, R. A., Littlejohn, R. L., \& RiGBY, R. L. (1977). Patterning, partial reinforcement, and N-length effects at spaced trials as a function of reinstatement of retrieval cues. Learning \& Motivation, 8, 77-97.

SPEAR, N. E. (1978). The processing of memories: Forgetting and retention. Hillsdale, NJ: Erlbaum.

Spear, N. E., Smith, G. J., Bryan, R. G., Gordon, W. C., Timmons, R., Chiszar, D. A. (1980). Contextual influences on the interaction between conflicting memories in the rat. Animal Learning \& Behavior, 8, 273-281. 
Thомas, D. R. (1981). Studies of long-term memory in the pigeon. In N. E. Spear \& R. R. Miller (Eds.), Information processing in animals (pp. 257-290). Hillsdale, NJ: Erlbaum.

Tномаs, D. R. (1985). Contextual stimulus control of operant responding in pigeons. In P. D. Balsam \& A. Tomie (Eds.), Context and learning (pp. 295-321). Hillsdale, NJ: Erlbaum.

Tulving, E. (1974). Cue dependent forgetting. American Scientist, 62, 74-82.
WAGNER, A. R. (1978). Expectancies and the priming of STM. In S. Hulse, H. Fowler, \& W. K. Honig (Eds.), Cognitive processes in animal behavior (pp. 177-209). Hillsdale, NJ: Erlbaum.

ZENTALL, T. R. (1970). Effects of context change on forgetting in rats. Journal of Experimental Psychology, 86, 440-448.

(Manuscript received October 14, 1992; revision accepted for publication October 12, 1993.) 